\title{
Evaluating Pre-Service Teachers' Design of Mathematical Modelling Tasks
}

\author{
Muhammed Fatih Dogan \\ Correspondence: mfatihdogan@adiyaman.edu.tr \\ Department of Mathematics and Science Education, Adiyaman University, Adiyaman, Turkey
}

\begin{abstract}
This study aims to examine pre-service teachers' competencies in designing authentic mathematical modelling tasks. The participants of this study were 22 pre-service teachers enrolled in a mathematical modelling course during their second year in a mathematics teacher education program. The participants designed 20 problems, which were evaluated based on four criteria for mathematical modelling: reality, openness, complexity, and model eliciting. The results indicate that even though the participants were successful in developing problems that had real-world scenarios, only five of them were classified as modelling problems. The majority of the problems fulfilled the reality criterion (12 out of 17); only five of them fulfilled the criteria of openness and model eliciting, and only six of them fulfilled the criterion of complexity. These findings contribute to the importance of supporting teachers' competencies in the teaching and learning of mathematical modelling for integration into K-12 classrooms.
\end{abstract}

Keywords: mathematical modelling, pre-service teachers, task design

\section{Introduction}

Mathematical modelling is one of the popular topics in mathematics education that has become more prominent during the last decades, as it bridges between mathematics and the real world. Mathematical modelling requires making an explicit connection between mathematics and the real-world and is seen as a crucial standard for mathematical practices in the Common Core State Standards Mathematics (CCSSM; 2010). The Guidelines for Assessment and Instruction in Mathematical Modelling Education report defines modelling as a cyclic process that includes identifying the problem; making assumptions and identifying variables; mathematising the situation; analysing and assessing solutions; iterating the process; implementing the model; and reporting out results (Society for Industrial and Applied Mathematics \& Consortium for Mathematics and Its Applications [SIAM \& COMAP], 2016). Given the potential of modelling tasks for strengthening student mathematical learning, there is a growing consensus about the importance of integrating mathematical modelling in mathematical standards and curriculum in different countries (Borromeo Ferri, 2018; CCSSM, 2010; Cirillo, Pelesko, Felton-Koestler, \& Rubel, 2016; Galbraith, 2015; Albarracín \& Gorgorió, 2019). However, it is not clear how the inclusion of mathematical modelling in the curricula should occur to promote effective teaching. Preparing in-service and pre-service teachers to have adequate mathematical modelling skills and implementing modelling tasks in classrooms is key for the effective integration of mathematical modelling into mathematical education programs at all levels. Including mathematical modelling in curricula and books is not enough to integrate mathematical modelling into school mathematics, as the most important element for supporting mathematical modelling is the teacher, and teachers at all levels need to be prepared to effectively teach modelling (Borromeo Ferri, 2018; Niss, Blum 
\& Galbraith, 2007). The teacher education programs need to ensure pre-service teachers have the necessary competencies for teaching mathematical modelling effectively in their classrooms.

This paper specifically focuses on the task dimensions of mathematical modelling (Borromeo Ferri, 2018), and investigates how pre-service teachers engage in designing modelling tasks. In teaching and learning, mathematical modelling tasks are the core of lessons as the quality of the task directly affects instruction and students' mathematical understanding and proficiency, especially given that such tasks are generally cognitively demanding (Stein, Grover, \& Henningsen, 1996). Pre-service teachers must be able to design modelling tasks to effectively engage their students in the process of mathematical modelling. The purpose of this study is to examine pre-service teachers' competencies in designing authentic mathematical modelling tasks. The ability to prepare mathematical modelling activities is an important component that will reveal the teacher's modelling knowledge as it allows the teacher to integrate students' learning in the classroom activity. However, designing a good mathematical modelling problem is a challenging task especially for pre-service teachers (PSTs) who do not have enough experience in the teaching and learning of modelling. Therefore, analysing modelling tasks designed by PSTs may offer important insights for teachers' educators regarding PSTs' knowledge and development on mathematical modelling.

\section{Literature Review and Theoretical Framework}

Mathematical Modelling. While there is a consensus about the importance of mathematical modelling, there is no common consensus on the definition of mathematical modelling. Modelling has been described as a creative process that allows learners to engage in a real-world problem that requires mathematising the situation to solve it (Blum \& Borromeo Ferri, 2009; English, 2003; Lesh \& Doerr, 2003), and to both understand the current situation and predict relevant future situations (Cirillo et al., 2016; Albarracín \& Gorgorió, 2019). This cyclical process is repeated between the real world and the mathematical world, but it starts in the real world and ends in the real world (Edwards \& Hamson, 2007). Thus, the repeated transitions back and forth between realworld and mathematics are a crucial component of mathematical modelling. The modelling process needs to start with a messy real-world problem that has no uniquely correct answer (Cirillo et al., 2016). Borromeo Ferri (2018) points out that "Appropriate modelling problems are the key instruments for reality-based lessons and understanding the criteria for modelling tasks is important" (from the Preface, p. x), and notes that pre-service teachers have to able to both design appropriate modelling tasks and understand the criteria for modelling tasks to effectively teach to their students.

Teachers' Competencies in Mathematical Modelling. Borromeo Ferri and colleagues (2014; 2018) identify four dimensions that include teachers' competencies for effective teaching, namely theoretical, task, instruction, and diagnostic dimensions (Blum \& Borromeo Ferri, 2009; Borromeo Ferri, 2014). The theoretical dimension of teacher competencies highlights the purpose of modelling and different perspectives of modelling. The task dimension includes the skills of solving mathematical modelling activities and creating different models, evaluating problems in terms of mathematical modelling and preparing activities. These two dimensions can be seen as teachers' stages of forming mathematical modelling ideas. Borromeo Ferri (2018) points out that task dimension is the link between theory and practice, as teachers need to consider the question of authenticity and complexity while designing their modelling problems. The practical skills 
required by teachers who have gained individual experience in mathematical modelling are included in the instruction dimension. This dimension focuses on the competencies of teachers to prepare a lesson plan in which they will use modelling tasks, guide the students in the classroom in the process of implementation, and support and provide feedback to those students. The diagnostic dimension includes the steps of following the modelling process as the students go through the task, identifying the difficulties of evaluating the students' work during and after the implementation process. Borromeo Ferri (2018) emphasizes that these competencies are not ordered and separated by sharp lines. Therefore, these four dimensions should not be considered independent of each other.

Modelling Task in the curricula. The modelling problems require creative thinking, have more than one starting point and need novel approaches to authentically connect real-world and mathematics. Thus, modelling problems are quite different and more complex than typical problems found in mathematics textbooks. Indeed, several studies have found that most of the textbooks offer limited opportunities to engage students in modelling activities (Çavuş-Erdem, Doğan, Gürbüz, \& Şahin, 2017; Germain-Williams, 2014; Meyer, 2015). Çavuş-Erdem et al. (2017) analysed Turkish middle school mathematics textbooks and found no modelling activities. Their findings showed that textbooks use the word "modelling" to represent modelling mathematics rather than mathematical modelling. Similarly, Meyer (2015) and Germain-Williams (2014) found very limited opportunities in Common Core-aligned textbooks in the USA. In both studies, the problems in the textbooks did not align with the cyclical nature of mathematical modelling and properties of modelling tasks. Even though mathematical modelling (Model with mathematics-MP4) is one of the eight mathematical practices emphasised in Common Core, the mere presence of modelling activities in textbooks is insufficient to support the effective implementation of modelling into classrooms. This highlights an important challenge for teachers when enacting modelling activities into their classrooms: they need to both understand mathematical modelling themselves and be able to design or select authentic modelling tasks for their students. Thus, for teaching modelling competencies to their students, teachers need to first select appropriate tasks, which requires that they be able to determine the properties of modelling tasks and distinguish them from traditional tasks. To accomplish this, teachers need to have content knowledge about mathematical modelling, such as the aim and perspectives of modelling, modelling cycles, and types of modelling tasks, how to prepare and implement appropriate lesson plans for modelling, how to evaluate students' modelling process and recognise their difficulties and mistakes, and how to design modelling tasks.

The decision of what to implement in the classroom as mathematical tasks strongly influences student learning (Henningsen \& Stein, 1997; Paolucci \& Wessels, 2017). Thus, teachers need to be able to design effective mathematical modelling tasks to promote students' learning with welldeveloped modelling skills. However, both pre-service and in-service teachers have difficulties posing problems, especially mathematical modelling problems, and implementing those problems in the classrooms (Borromeo Ferri, 2018; Galbraith, 2007, 2012). Designing mathematical tasks is regarded as high-leverage practice (Ball, Thames, \& Phelps, 2008) and is seen as an important process in both pre-service and in-service teachers' development and learning (Hošpesovà, \& Tichà, 2015; Paolucci \& Wessels, 2017; Schukajlow, Kaiser, \& Stillman, 2018; Tichà \& Hošpesovà, 2010). More specifically, designing authentic mathematical modelling tasks may be a 
vital ability for teachers as it offers rich opportunities for $21^{\text {st }}$ century abilities (Paolucci \& Wessels, 2017).

Characteristics of Mathematical Modelling Tasks. There are several features highlighted in the literature about characteristics of mathematical modelling tasks (Borromeo Ferri, 2018; Galbraith, 2007, 2012; Lesh, Hoover, Hole, Kelly \& Post, 2000; Maaß, 2007). The first feature is having a real-world problem situation which is a sine qua non-component that arises from the assumption that traditional problems are inadequate in developing students' ability to use mathematics in the real world. There are two issues emphasised by real-world situations in modelling problems. Scenarios in traditional word problems dealing with the real world within clear limits, as students who engage in such questions, may ignore the possibilities and limitations of these kinds of problems when faced with real-world situations. Therefore, it is important that mathematical modelling problems should be handled with the components of real-world problem situations, and that the problem situation overlaps with real-world (Galbraith, 2012; Lesh et al. 2000). Another point that is emphasised about the real-world situation in modelling problems is that the scenario in the case of a problem should align with the reality of the practicing group.

In modelling problems, individuals are asked to present a mathematical solution to the problem. The individuals need to make sense of the real-world situation to be able to engage with ideas and reach the desired solution. This requirement, which Lesh et al. (2000) called the principle of reality, is an important issue emphasised by other studies defining the characteristics of modelling tasks (Borromeo Ferri \& Lesh, 2013; Galbraith, 2012; Maßß, 2007, 2010). Another feature sought in modelling tasks is that it allows students to form a mathematical model that can answer the realworld situation. In other words, in mathematical modelling tasks, the learners should feel the need to use mathematical ways to solve the real-world problem and present a mathematical solution plan (Lesh et al. 2000). To do this, the learners need to interpret the problem situation, identify the components that affect the problem and make assumptions to craft the solution. Galbraith (2012) stated that mathematics in modelling problems will emerge by interpretation and therefore interpretation is very important for seeking a mathematical solution. Furthermore, mathematical modelling tasks should be open-ended, interpretable and contain different solution paths (Galbraith, 2012; Lesh \& Doerr, 2003; Maßß, 2007). The model that emerges in modelling problems should be an effective solution for similar problem situations and should be generalisable in this aspect. Another feature that is sought in modelling problems is that the structure of the problem provides the individuals with an opportunity to evaluate. The mathematical model introduced should be interpretable with regards to the real world as well as being mathematically feasible. In other words, individuals should be able to evaluate the mathematical accuracy of the particular model and whether it is suitable in the real world and reach the conclusion that the solution is sufficient. This feature, which is named in the literature as the self-evaluation principle (Lesh et al., 2000), is another feature sought in modelling tasks. Maaß (2007) defined the properties of mathematical modelling problems and emphasised that solving the problem in accordance with the modelling process is an important feature in defining the problem. Overall, the literature emphasises the importance that the modelling process consists of certain stages such as understanding the problem, mathematising the problem based on the assumptions and creating a model, solving the model, and interpreting and evaluating the real world (Borromeo Ferri, 2018, 2006; Doğan, Gürbüz, Çavuş-Erdem, Şahin, 2019; Lesh \& Doerr, 2003). 
When we look at the characteristics of the above-mentioned modelling tasks, the features overlap with the stages of the modelling process. Such that; the real-world situation in the modelling problem overlaps with the reality of the individual, and the problem is an open-ended, interpretable structure and requires a solution formed by mathematical means, the model creates and solves the model, and the problem presents an opportunity to evaluate the model, and the interpretation and evaluation of the model can be expressed in relation to the stages. From this point of view, modelling problems that provide the aforementioned features naturally provide the ability to be solved in accordance with the modelling process.

What counts as a mathematical modelling task is an important question that needs to be answered both by researchers and teachers. In particular, teachers need to clearly distinguish between mathematical modelling tasks and traditional tasks to have effective teaching of mathematical modelling in the classroom. Some important criteria for mathematical modelling tasks highlighted in the relevant literature was listed above, including Reality, Openness, Complexity, and Model Eliciting. Tasks designed following these criteria will generally provide meaningful opportunities for students to engage in modelling activities. The purpose of this study was to examine tasks designed by PSTs in terms of these modelling criteria.

\section{Method}

This study was conducted in an interpretive paradigm by using document analysis (Cohen, Manion \& Lawrence, 2007; Creswell, 2003). The unit of analysis was individual mathematical modelling tasks designed by pre-service teachers. The tasks were coded by applying criteria that were synthesised from the literature (Borromeo Ferri, 2018; Doerr \& Lesh, 2011; Galbraith, 2007; Maßß, 2007).

\section{Research Context and Participants}

The data were collected from an elective course called Mathematical Modelling and Its Applications. The participants of this study were 22 pre-service teachers in a mathematics education program in Turkey. All participants were in the second year of the teacher education program and enrolled in the Mathematical Modelling course for 14 weeks. The course focused on mathematical modelling and aimed to support PSTs' knowledge of mathematical modelling and how to use it in their classrooms. The course was designed based on Borromeo Ferri's (2018) model that emphasises both theoretical and practical dimensions of mathematical modelling competencies. The PSTs had opportunities to learn theoretical background about modelling, solving and developing modelling problems, and instructional practices to teach modelling in their future classroom. PSTs were first asked to compare two problems "A clear day at the ocean" and "Port of Hamburg" (Borromeo Ferri, 2018) to analyse differences between traditional problems and mathematical modelling problems. After that, they were given a mathematical modelling activity to work on in the class and another one as homework for each week. Most of the work in the classroom was completed in groups of 3 or 4 . During the coursework, PSTs had opportunities to read literature about mathematical modelling, to solve mathematical modelling tasks, to evaluate them, and to design mathematical modelling tasks. The PSTs engaged in different modelling perspectives and discussed the difference between mathematical modelling and different problemsolving approaches (including traditional problems). Thus, they had opportunities to explore, reflect on and evaluate examples of mathematical modelling tasks. After engaging in different 
aspects of mathematical modelling, PSTs were asked to write an authentic mathematical modelling task as a final project for the course and given five weeks to design the task. During these five weeks, PSTs continued to work on engaging in different mathematical modelling tasks and to discuss the features of those tasks. Additionally, there was a class session each week devoted to discussing the PSTs' process on their task design. PSTs were asked to create a modelling task for a specific grade, concerning a mathematical topic during the sixth week of the class and to finalise the task by the $12^{\text {th }}$ week of the class. Designing a modelling task was challenging for most of the PSTs, as they needed to think about the school level, the authenticity of the problem, the mathematical context of the problem, and fulfilling the criteria for modelling problems. Thus, having enough time to design a modelling task was very important for PSTs to create a modelling problem.

\section{Data Analysis}

The tasks developed by PSTs were analysed by using modelling task criteria as aforementioned (Borromeo Ferri, 2018; Doerr \& Lesh, 2011; Galbraith, 2007; Maaß, 2007). The criteria used for analysis were Reality, Openness, Complexity, and Model Eliciting. Table 1 shows each code with the explanation of the code and the questions seeking for the criteria.

Table 1. Criteria of mathematical modelling tasks

\begin{tabular}{|c|c|c|}
\hline $\begin{array}{l}\text { Criteria for } \\
\text { Modelling } \\
\text { Problems } \\
\end{array}$ & Explanation & $\begin{array}{l}\text { The guiding questions for the } \\
\text { criteria }\end{array}$ \\
\hline Reality & $\begin{array}{l}\text { The problem includes a real-world } \\
\text { situation and the problem situation } \\
\text { overlaps with the reality of the } \\
\text { individual }\end{array}$ & $\begin{array}{l}\text { - Does the problem involve a real- } \\
\text { world situation? } \\
\text { - Does the problem situation } \\
\text { include information and } \\
\text { explanation that may be } \\
\text { meaningful to the individual? }\end{array}$ \\
\hline Openness & $\begin{array}{l}\text { Problem is based on assumptions } \\
\text { and predictions (interpretation) and } \\
\text { opens to different and original } \\
\text { solutions }\end{array}$ & $\begin{array}{l}\text { - Is the problem suitable for } \\
\text { interpretation and assumption? } \\
\text { - Are there different solutions to } \\
\text { the problem? }\end{array}$ \\
\hline Complexity & $\begin{array}{l}\text { Having implicit mathematics in the } \\
\text { problem and the individual's desire } \\
\text { or need to solve the problem }\end{array}$ & $\begin{array}{l}\text { - Does the individual feel the need } \\
\text { to use mathematical ways to solve } \\
\text { the problem? } \\
\text { - Does the problem cause a feeling } \\
\text { of complexity or helplessness for } \\
\text { the individual? }\end{array}$ \\
\hline Model Eliciting & $\begin{array}{l}\text { Solving the problem according to } \\
\text { the mathematical modelling process }\end{array}$ & $\begin{array}{l}\text { - Can the problem be solved by } \\
\text { mathematising the real-world } \\
\text { situation? }\end{array}$ \\
\hline
\end{tabular}

The PSTs developed 20 problems in total and all problems were evaluated based on the criteria in Table 1 by three researchers. After coding the data individually, the researchers come together and 
discussed their reasonings for the criteria, then the final decision was given as to whether the problem fulfilled the criteria. Out of those 20 problems, one of them was inspired by an existing mathematical modelling task in the literature, and two of them were directly copied from different sources. Thus, we did not include these 3 problems in the analysis, resulting in a data corpus of 17 problems.

\section{Results}

The results of this study revealed the criteria that were enacted by PSTs while designing mathematical modelling tasks. In this section, first, the examples of PSTs modelling tasks will be presented to explain how they used criteria in their task design, and then the general results will be provided.

PSTs designed three different task types: unsuccessful modelling problems, partly successful modelling problems, and successful modelling problems. The unsuccessful modelling problems that have no potential to become authentic modelling tasks fail to fulfill most of the modelling criteria, while partly successful modelling tasks fulfill some of the modelling criteria but not all and could be converted to a modelling problem. The five examples of mathematical modelling tasks given below are all produced by the PSTs, and were sufficiently novel to be included in the data corpus of 17 examples. These five examples were chosen specifically because they illustrate the broader patterns of competencies found in the overall evaluation of examples (see Table 1). Consequently, while two of these examples satisfy the overall criteria, we focus here also on examples that do not satisfy the criteria, in order to illustrate struggles that the PSTs had with authentic mathematical modelling. The following problems offer examples of unsuccessful modelling problems created by PSTs. One example of an unsuccessful problem is School Road Problem:

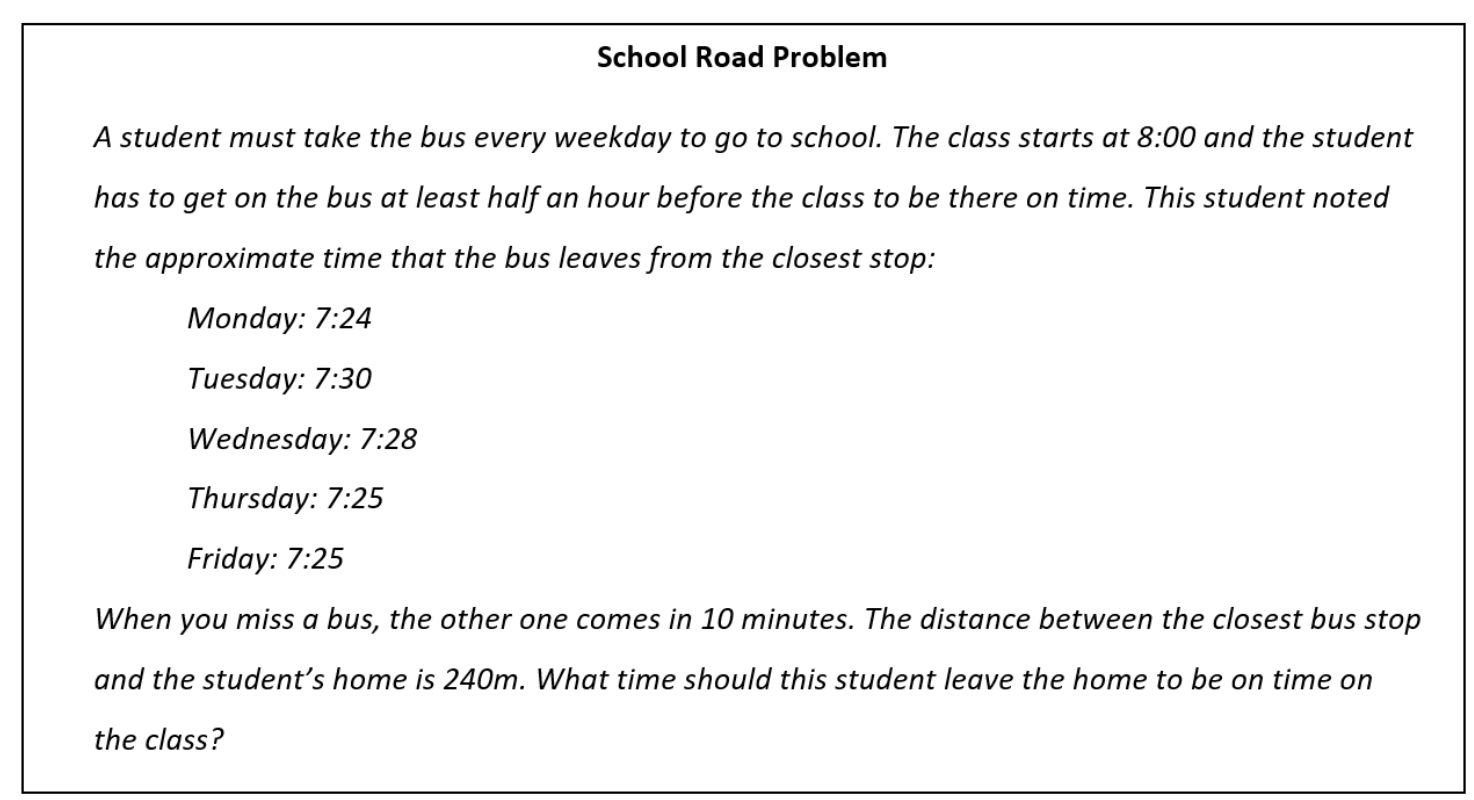

The task "School Road Problem" is a typical task that can be seen in several textbooks and has a real context. Even though the context offers an example of the real phenomenon, it is limited as it 
does not require making assumptions since the real situation is already simplified in the context. The student only needs to determine how many minutes it would be possible to walk $240 \mathrm{~m}$ by calculating the number of seconds to take a step. As all required numeric data are given, the problem cannot be solved based on a modelling process. Even though we do not know the distance between the bus stop and the school, the problem does not require considering this relation at all, so there is no need for making that kind of assumption. There are a lot of variables such as traffic jams, road construction that might affect the time between the bus stop and the school, thus, the connection between the real-world and mathematics is not established in the problem. Therefore, this task is not counted as a modelling problem, as the students do not pass through all the modelling process/cycle and the connection between reality and mathematics is broken.

Another example is Clothes Charity Problem:

\section{Clothes Charity Problem}

A Social Assistance and Solidarity Foundation want to provide winter coats and scarf-beret-gloves set charity to the students of a village school in the Eastern Anatolia Region. This foundation will spend a certain amount on its own budget for this charity. The foundation asks its employees to calculate the expenditure for this charity. The foundation makes a deal with a local provider for the clothes and prices agreed as follow:

There are 3 sizes for coats (6-8), (9-11) and (12-13) years old.

Coat price for (6-8) age range: 60TL

Coat price for (9-11) age range: $70 T L$

Coat price for (12-13) age range: $70 T L$.

For Scarf-beret-glove set, there is no price difference according to size. Each set is $20 \mathrm{TL}$.

Your job is to calculate the potential expenditure for this charity.

The Clothes Charity Problem asks students to determine the cost of a charity and fulfills the principle of reality. However, the problem struggles with being open-ended as it does not allow students to make assumptions as it differs only with numerical variables. The problem solver may need to determine the number of students, but the mathematical process is limited to multiplying the given prices with the number of students in each age group. Therefore, the problem does not fulfill the openness criterion. Also, it does not have a thought-provoking process and the solution can be found immediately by making a routine calculation based on the number of students in each age group. Thus, the problem does not allow for model eliciting. As a result, this problem cannot be accepted as a modelling problem.

The following Library Problem designed by one of the PSTs is not considered a mathematical modelling problem, but it is different to the unsuccessful examples, as it can be easily modified to a modelling problem: 


\section{Library Problem}

A library will be opened in the Faculty of Education. The number of bookshelves and book types in the library are known and you are asked to find the number of books that can be placed in the library, provided that each bookshelf has the same type of book. How would you solve this problem as mathematical modeling?

NOTE: The bookshelves have eight compartments, four on the front and four on the back. The numbers of bookshelves are six pieces. The length of each bookshelves compartment is given in $\mathrm{cm}$.

When reading the problem, it looks like it fulfills the criterion for reality, as it might be particularly relevant to the reality of children at the primary school level. However, the reality of the problem is not appropriate for the secondary student level and the model they might form does not make sense in the real world as it has a lot of restrictions. Therefore, the problem only partly fulfilled the reality criterion. The reality of the problem needs to be balanced with the application group, which is not the case here as the context of this problem does not offer much to students to solve the problem and make the appropriate connection between mathematics and the real-world. Also, the problem does not allow learners to make assumptions as in the note section the required knowledge to solve the problem is provided. Thus, the problem is not open to interpretation or assumptions. Even though the problem is complex for the primary school level, it is not complex or complicated enough for secondary school students. The problem does not allow model eliciting as it is restricted for assumptions and acquires a certain result. Thus, the problem was not accepted as a modelling problem, but with some modifications, this problem can be transformed into a modelling problem.

When we look at those problems above, the main limitations are the lack of making assumptions and the connection between reality and mathematics. The following problems are different from those problems and offer examples of successful modelling problems created by PSTs with identifying the criteria of the tasks. One example is Land Problem:

\section{Land Problem}

Mr. Eyup wants to buy a land to use as outdoor car parking. However, he cannot decide how much land to buy. He decided to purchase a plot of land where 50 cars can be parked easily. What do you think that how much land Mr. Eyup needs to buy to makes his plans real as he wishes?

By providing only relevant data to make assumptions, the problem requires students to develop a model. It provides the opportunity to determine different variables such as the required free space, parking distance, type of cars when parking cars. It also has a real context that students need to mathematise to make the connection between reality and mathematics, and need to go through all modelling cycles. The student has to determine the mathematical algorithm s/he will use in the solution of the problem depending on the different variables considered. This implies that it has a 
complex nature for students as they have to search for relevant data and feel the need for mathematics to solve the problem. In addition, there is no mathematical rule given to solve the problem, which makes it an open problem. Thus, this problem fulfills all criteria to be counted as an authentic modelling problem.

Another example of a successful modelling problem designed by PSTs is named Mosque Carpet Problem:

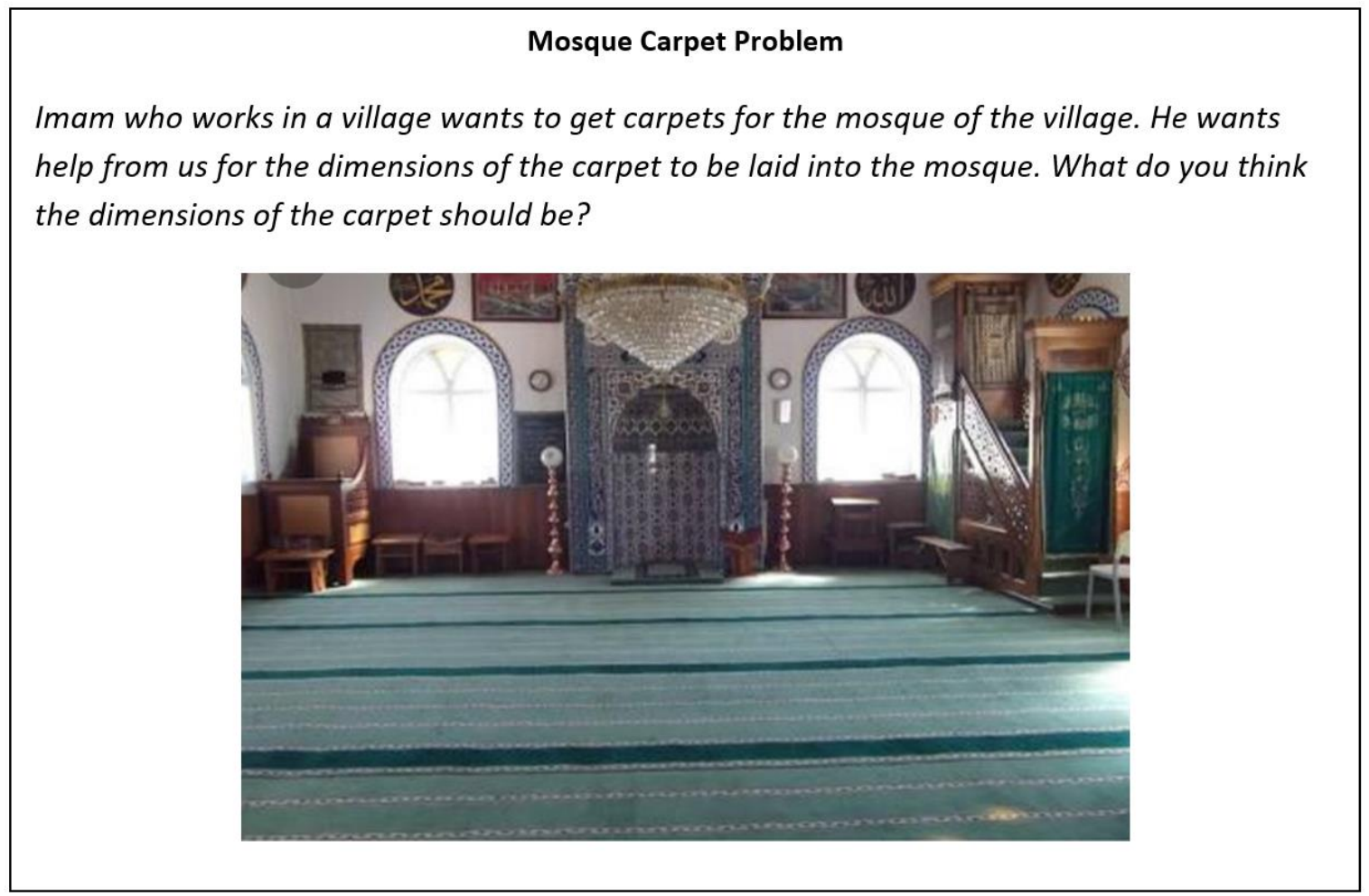

Mosque Carpet problem involves the determination of the dimensions of the carpet covering the floor of a mosque and includes a scenario of the real-world. The mosques, which can be found in almost all parts of the country, are generally an architectural structure where students at the secondary level know. In this sense, it can be said that the problem involving the laying of the mosque carpet coincides with the reality of the student and provides the reality principle. Besides, the variables affecting the design of the mosque, the population of the village, the male-female sections in the mosque and determining the dimensions of the carpet are left to the student and are open to assumptions. In addition, these variables are not explicitly stated in the statement of the problem. In other words, the student should determine the necessary variables to form a model and make realistic assumptions about these variables. These explanations show that the problem meets the criteria of openness and complexity. In the problem, students have to make mathematical calculations to determine the size of the carpet. For example, the student can form a model based on the area a person can fit. Here, the student needs to make use of the ratio to form a meaningful solution, that is, to express and solve the problem mathematically. In short, the problem allows students to create a mathematical model, determine variables, and reach a mathematical solution. Therefore, it can be considered as a mathematical modeling problem. 
As can be seen from the examples, PSTs enacted different modelling criteria while designing authentic tasks. Table 2 shows the frequency of criteria used by PSTs.

Table 2. The number of problems for each modelling criteria (out of 17).

\begin{tabular}{lcccc}
\hline & Reality & Openness & Complexity & Model Eliciting \\
\hline Yes & $12(70 \%)$ & $5(29 \%)$ & $6(35,5 \%)$ & $5(29 \%)$ \\
No & $4(24 \%)$ & $10(59 \%)$ & $5(29 \%)$ & $11(65 \%)$ \\
Partly & $1(6 \%)$ & $2(12 \%)$ & $6(35,5 \%)$ & $1(6 \%)$ \\
\hline
\end{tabular}

As can be seen in Table 2, the reality principle was most often applied when creating modelling problems. 12 of the problems fulfilled the reality principle, while 4 of them did not have real-world contexts. One of the problems only partly fulfilled the reality principle since the link between reality and mathematics was not established sufficiently to develop a model that makes sense in the real world.

Openness was another criterion considered by PSTs while designing the tasks. As can be seen from Table 2, only 5 of the problems fulfilled the openness principle, and most of them (10) did not allow for making assumptions or predictions and different solutions for the problem. Two of the problems partly fulfilled the openness principle as they had limited opportunities for making assumptions since the problems provided all needed data to achieve a solution.

Another important feature of mathematical modelling tasks is being complex enough that the solver needs to develop mathematical models to resolve the real-world situation. Only 6 problems fulfilled the complexity criterion, while 6 of them partly fulfilled this principle. 5 of the problems did not fulfill the complexity criterion.

The final criterion that was considered by PSTs was model eliciting. Only 5 problems could be solved based on the mathematical modelling process, while one problem partly fulfilled this criterion. Interestingly, 11 of the problems could not be solved according to the mathematical modelling process, as they failed to allow for the creation of mathematical models and did not have an appropriate connection between real-world and mathematics.

Overall, the results showed that only 5 out of 17 problems fulfilled the criteria for modelling problems (Table 2).

As shown in Table 3, the tasks accepted as a modelling problem fulfilled all four criteria, namely, Reality, Openness, Complexity, and Model Eliciting. These tasks were counted as successful modelling problems. 11 tasks did not fulfill at least one of the criteria to be counted as a modelling problem. These tasks were counted as unsuccessful modelling problems. Finally, one task partly fulfilled the criteria, Library Problem, which means with the required modification, this problem can be converted to a modelling task. Thus, PSTs designed three different task types: successful modelling problems, unsuccessful modelling problems, and partly successful modelling problems. 
Table 3. The Evaluation of the problems based on the modelling criteria

\begin{tabular}{|c|c|c|c|c|c|c|}
\hline No. & Name of the Problem & Reality & Openness & Complexity & $\begin{array}{l}\text { Model } \\
\text { Eliciting }\end{array}$ & $\begin{array}{c}\text { Is it a } \\
\text { modelling } \\
\text { problem }\end{array}$ \\
\hline 1. & Library Problem & Partly & Partly & Partly & Partly & No \\
\hline 2.* & Birthday Cake Problem & Yes & Yes & Yes & Yes & Yes \\
\hline $3 .^{*}$ & Land Problem & Yes & Yes & Yes & Yes & Yes \\
\hline 4. ${ }^{*}$ & Puduhepa Dolls Problem & Yes & Yes & Yes & Yes & Yes \\
\hline $5 * *$ & Kennel Problem & Yes & Yes & Yes & Yes & Yes \\
\hline 6. & $\begin{array}{l}\text { Paid Military Service } \\
\text { Problem }\end{array}$ & No & No & No & No & No \\
\hline 7. & $\begin{array}{l}\text { University Enterance Exam } \\
\text { problem }\end{array}$ & No & No & No & No & No \\
\hline 8. & Dormitory Problem & Yes & No & Partly & No & No \\
\hline 9. & Emin's Dormitory Problem & Yes & No & No & No & No \\
\hline $10 * *$ & Mosque Carpet Problem & Yes & Yes & Yes & Yes & Yes \\
\hline 11. & School Road Problem & Yes & No & Partly & No & No \\
\hline 12. & Clothes Charity Problem & Yes & No & Partly & No & No \\
\hline 13. & Airport Problem & Yes & No & No & No & No \\
\hline 14. & Pistachio Garden Problem & Yes & No & Yes & No & No \\
\hline 15. & Final Exam & No & No & Partly & No & No \\
\hline 16. & Graduation Problem & No & Partly & Party & No & No \\
\hline 17. & Factory Shift Problem & Yes & No & No & No & No \\
\hline
\end{tabular}

* Accepted as a mathematical modelling problem

\section{Discussion}

The purpose of this study was to investigate the criteria PSTs use while designing authentic mathematical modelling problems. The ability to prepare mathematical modelling activities is an important component that will reveal the teacher's modelling knowledge. However, designing mathematical modelling problems is not an easy task since it requires making meaningful connections between real-world situations and mathematics as well as allowing students to mathematise the real-world situation. The PSTs were relatively successful with designing problems, but not all problems created by them fulfilled the modelling criteria. 
As mathematical modelling involves solving problems in the real-world by mathematising the situation (de Almeida \& da Silva, 2015), the first feature that needs to be discussed during the cognitive analysis of a problem is its relevance to the real world. The feature of reality means that the problem is a part of the real world as the solution of the problem fits into the reality (Bonotto, 2007; Paolucci, \& Wessels, 2017; Şahin, 2019) and there is an appropriate connection between mathematics and real-world (Borromeo Ferri \& Lesh, 2013; Galbraith, 2007). The results of this study show that PSTs were proficient in creating their problems in terms of having meaningful context for real-world situations and mostly considered the relationship between mathematics and reality. Although the real world is the basis of all problems, the principle of reality is not handled as expected in every problem. 12 of the problems developed by PSTs fulfilled the reality criterion as in Land Problem and Mosque Carpet problem, while four of them did not have realistic contexts. One problem, Library Problem, had partially fulfilled the reality criterion, as it did not consider the context of students' real-world perception. The relationship between mathematics and the real world requires that the solution be meaningful in both worlds (Galbraith, 2007, 2015). Both the outside world and mathematics are emphasised in the modelling process and solutions need to be mathematically correct and reasonable in the real world. As can be seen in Land Problem and Mosque Carpet problem, the students would need to make reasonable assumptions and create models to solve these problems while always considering the connection between mathematics and the real world. However, when we looked at the other problems, they failed to fulfill the reality criterion. Paolucci and Wessels (2017) found similar results in their study as most of their participants created realistic scenarios but failed to make connections between reality and mathematics. To design an authentic modelling problem, the designer of the task needs to consider the possible solutions to strengthen the real-world connections.

Another important feature of mathematical modelling tasks is having a thought-provoking and complex nature (Blum \& Borromeo Ferri, 2009; Garfunkel \& Montgomery, 2016). This is defined as creating a feeling of insecurity and the need for mathematics for a solution (Galbraith, 2007; Kaiser, Schwarz \& Buchholtz, 2011). As it is stated by Blum and Borromeo Ferri (2018), "A modelling problem should always be a problem in the sense that you can't find the solution immediately by routine activities, but have to think about strategies for reaching the solution" ( $\mathrm{p}$. 47, italics original). The results of this study showed that only 6 of the problems fulfilled the criterion of complexity, while 5 of them failed in this sense. The remaining 6 of the problems developed by PSTs were partly complex and by modifying the context, this could be improved. There may be various reasons for such a result. One of them may be that PSTs misinterpreted the criterion of being complex when preparing a modelling problem as being unsolvable or confusing in the sense that the problem fails to make mathematical interpretations possible. As in Sahin's (2019) study, PSTs may have the illusion that a problem must be difficult to be counted as a modelling problem.

In addition, participants may not have understood that when preparing a mathematical modelling problem, it should not be a traditional problem that can be solved in a few simple mathematical steps. Sahin, Dogan, Cavus-Erdem, Gurbuz, and Temurtas (2019) showed that PSTs think that the problems that require many mathematical operations can be mathematical modelling problems as they cannot be solved in a few steps. As it can be seen from the School Road Problem and Clothes Charity Problem, both of them were simplified to mathematical operations and were far from being complex. But, when we consider the Land Problem and Mosque Carpet problem, both are not 
easily solvable by routine activities and the solver needs to make assumptions and create models to solve the problems. Thus, these two problems are open, which distinguishes mathematical modelling problems from traditional problems. The openness of the problem is related to assumptions and predictions and to allow for unique solutions (Borromeo Ferri, 2018; Maaß, 2007, 2010). The results of this study showed that only 5 of the problems fulfilled the openness criterion, while 12 of them failed to allow making assumptions and predictions to solve the problem. Both the School Road Problem and Clothes Charity Problem presented almost all the required data to solve the problem, so the problem solver only needs to do mathematical calculations, instead of developing a unique mathematical model.

Indeed, many of the PSTs tried to leave the determination of the variables necessary for the solution to the problem solver, but they cannot move beyond assigning a simple numeric value to the variable such as determining the number of students in the Clothes Charity Problem. For example, if the problem solver changes the number of students in their equation, they might get different results as a final answer. Otherwise, the problem would be transferred to mathematical language rather than mathematising the real-world situation. Mathematisation is not an act of translation into simple mathematics, but rather the task of organising mathematics (Djepaxhija, Vos, \& Fuglestad, 2017) and this process should encourage students to think mathematically and generate ideas (English \& Sriraman, 2010). This is also related to creating mathematical models to solve a real-world situation and supporting students' learning by giving them the agency of their learning. The results showed that only 5 of the problems allowed for creating models, while most of them (11 out of 17) failed to provide opportunity for model eliciting. Paolucci and Wessels (2017) also found that PSTs had difficulties in designing model eliciting activities. On the other hand, Sahin (2019) found that in-service teachers who attended a workshop on mathematical modelling were successful in designing modelling tasks, but warned that the teachers mostly had a limited understanding of criteria of modelling tasks. Therefore, both in-service teachers and PSTs should have more opportunities in mathematical modelling that is not limited to a term or short duration of time.

\section{Conclusion}

This study aimed to investigate pre-service teachers' (PSTs) competencies in designing authentic mathematical modelling tasks. The findings of this study highlight important results about what constitutes mathematical modelling tasks for PSTs. Designing mathematical modelling problems was a big challenge for PSTs. This raises some important questions about how the inclusion of mathematical modelling should occur in the classroom to promote effective teaching. The relevant research reveals that both in-service and pre-service teachers do not have adequate mathematical modelling skills and ability in implementing modelling tasks in their classrooms. Besides, the curricula and textbooks do not have the required support, such as modelling tasks, for teachers for effective integration of mathematical modelling into the classrooms at all levels. Therefore, having competencies to design mathematical modelling tasks seems to have crucial importance for integrating mathematical modelling in the classrooms. The criteria used to evaluate mathematical modelling tasks in this study can be considered as theoretical criteria for modelling problems. Teachers and pre-service teachers need to have the necessary competencies for teaching mathematical modelling effectively in their classrooms. Thus, the teacher training programs (both professional development and teacher education programs) may use the criteria to design 
modelling courses in order to prepare them to effectively teach modelling. However, this study only focused on the tasks designed by PSTs, and there is an urgent need to conduct more research on how teachers design modelling tasks and how they enact those tasks in their classrooms. Also, there is more research needed on how to integrate mathematical modelling tasks into both teacher education programs and K-12. Given the importance of mathematical modelling, we are failing our students when we do not teach our teachers how to do this in their classrooms.

\section{References}

Albarracín, L., \& Gorgorió, N. (2019). Using large number estimation problems in primary education classrooms to introduce mathematical modelling. International Journal of Innovation in Science and Mathematics Education, 27(2), 33-45.

Ball, D.L., Thames, M. H., \& Phelps, G. (2008). Content knowledge for teaching: What makes it special? Journal of Teacher Education, 59(5), 389-407.

Blum, W., \& Ferri, R. B. (2009). Mathematical modelling: Can it be taught and learnt? Journal of Mathematical Modelling and Application, 1(1), 45-58.

Bonotto, C. (2007). How to replace word problems with activities of realistic mathematical modelling. In Modelling and applications in mathematics education (pp. 185-192). Springer, Boston, MA.

Borromeo Ferri, R. (2006). Theoretical and empirical differentiations of phases in the modelling process. ZDM, $38(2), 86-95$.

Borromeo Ferri, R. (2014). Mathematical modelling - The teachers' responsibility. In A. Sanfratello and B. Dickman (Ed.), Proceedings of conference on mathematical modelling at Teachers College of Columbia University (p. 26-31). New York.

Borromeo Ferri, R. (2018). Learning how to teach mathematical modelling in school and teacher education. Springer International Publishing.

Borromeo Ferri, R., \& Lesh, R. (2013). Should interpretation systems be considered as models if they only function implicitly? In G. Stillman et al. (Eds.), Teaching mathematical modelling: Connecting to research and practice (pp. 57-66). New York: Springer.

Cirillo, M., Pelesko, J., Felton-Koestler, M., \& Rubel, L. (2016). Perspectives on modelling in school mathematics. In Annual perspectives in mathematics education: Mathematical modelling and modelling mathematics (pp. 3-16). Reston: NCTM.

Cohen, L., Manion, L., \& Lawrence, K. (2007). Research methods in education. (6th ed.). Milton Park: Routledge.

Creswell, J. W. (2003). Research design: Qualitative, quantitative, and mixed methods approaches. (2nd ed.). Thousand Oaks, CA: Sage.

Çavuş-Erdem, Z., Doğan, M.F., Gürbüz, R. \& Şahin, S. (2017). Matematiksel modellemenin öğretim araçlarına yansımaları: Ders kitabı analizi. Adıyaman Üniversitesi Eğitim Bilimleri Dergisi, 7 (1), 61-86.

de Almeida, L. M. W., \& da Silva, K. A. P. (2015). The meaning of the problem in a mathematical modelling activity. In Mathematical Modelling in Education Research and Practice (pp. 45-54). Springer, Cham.

Djepaxhija, B., Vos, P., \& Fuglestad, A. B. (2017). Assessing mathematizing competences through multiple-choice tasks: Using students' response processes to investigate task validity. In Mathematical Modelling and Applications (pp. 601-611). Springer, Cham.

Doğan, M. F., Gürbüz, R, Çavuş Erdem, Z, Şahin, S. (2019). Using mathematical modelling for integrating STEM disciplines: A theoretical framework. Turkish Journal of Computer and Mathematics Education, 10 (3), 628-653.

Edwards, D., \& Hamson, M. (2007). Guide to mathematical modelling (2nd ed). New York: Industrial Press, Inc.

English, L. D. (2003). Reconciling theory, research, and practice: A models and modelling perspective. Educational Studies in Mathematics, 54(2-3), 225-248.

English, L. D., \& Sriraman, B. (2010). Problem solving for the 21st century. In B. Sriraman \& L. D. English (Eds.), Theories of mathematics education: Seeking new frontiers (Advances in Mathematics Education Series) (pp. 263-285). New York: Springer.

Galbraith, P. (2007). Dreaming a 'possible dream': More windmills to conquer. In C. Haines, P. Galbraith, W. Blum, \& S. Khan (Eds.), Mathematical modelling: Education, Engineering and Economics (pp. 44-62). Chichester, UK: Horwood. 
Galbraith, P. (2012). Models of modelling: Genres, purposes or perspectives. Journal of Mathematical Modelling and Application, 1(5), 3-16.

Galbraith, P. (2015). Modelling, education, and the epistemic fallacy. In G. A. Stillman, W. Blum, \& M. S. Biembengut (Eds.), Mathematical Modelling in Education Research and Practice: Cultural, Social and Cognitive Influences (pp. 339-350). New York: Springer.

Garfunkel, S., \& Montgomery, M. (2016). Guidelines for assessment and instruction in mathematical modelling education (GAIMME). Boston/Philadelphia: Consortium for Mathematics and Its Applications (COMAP)/Society for Industrial and Applied Mathematics (SIAM).

Germain-Williams, T. (2014). Mathematical modelling in algebra textbooks at the onset of the Common Core State Standards (Doctoral dissertation, Teachers College).

Henningsen, M., \& Stein, M. (1997). Mathematical tasks and student cognition: Classroombased factors that support and inhibit high-level mathematical thinking and reasoning. Journal for Research in Mathematics Education, 28(5), 534-549.

Hošpesovà, A., \& Tichà, M. (2015). Problem posing in primary school teacher training. In F. Singer, N. Ellerton, \& J. Cai (Eds.), Problem posing in mathematics: From research to effective practice (pp. 433-448). New York: Springer.

Kaiser, G., Schwarz, B., \& Buchholtz, N. (2011). Authentic modelling problems in mathematics education. In G. Kaiser, W. Blum, R. Borromeo Ferri, \& G. Stillman (Eds.), Trends in teaching and learning of mathematical modelling (pp. 591-601). New York: Springer.

Lesh, R., \& Doerr, H. M. (2003). Foundations of a models and modelling perspective on mathematics teaching, learning, and problem solving. Beyond constructivism: Models and modelling perspectives on mathematics problem solving, learning, and teaching (p. 3-33).

Lesh, R., Hoover, M., Hole, B., Kelly, A., \& Post, T. (2000). Principles for developing thought revealing activities for students and teachers. In A. Kelly \& R. Lesh (Eds.), Handbook of research design in mathematics and science education (pp. 591-645). Mahwah, NJ: Lawrence Erlbaum and Associates, Inc.

Maaß, K. (2007). Modelling in class: What do we want the students to learn? In C. Haines, P. Galbraith, W. Blum, S. Khan, \& Mathematical Modelling (Eds.), Education, engineering and economics (pp. 65-78). Chichester: Horwood Publishing.

Maaß, K. (2010). Classification scheme for modelling tasks. Journal für Mathematik-Didaktik, 31, 285-311.

Meyer, D. (2015). Missing the promise of mathematical modelling. Mathematics Teacher, 108(8), 578-583.

National Governors Association Center for best Practices and Council of Chief State School Officers (NGA Center and CCSSO). (2010). Common core state standards for mathematics. Washington, DC: NGA Center and CCSSO.

Niss, M., Blum, W., \& Galbraith, P. L. (2007). Introduction. In W. Blum, P. L. Galbraith, H.-W. Henn, \& M. Niss (Eds.), Modelling and applications in mathematics education: The 14th ICMI study (pp. 1-32). New York: Springer.

Paolucci, C., \& Wessels, H. (2017). An Examination of preservice teachers' capacity to create mathematical modelling problems for children. Journal of Teacher Education, 68(3), 330-344.

Sahin, S. (2019). Matematik ögrretmenlerinin matematiksel modelleme problemi hazırlama becerilerinin incelenmesi. Yayımlanmamıs Doktora tezi, Adıyaman Üniversitesi, Adıyaman, Türkiye.

Sahin, S., Dogan, M.F., Cavus Erdem, Z., Gurbuz, R., \& Temurtas, A. (2019). Prospective teachers' criteria for evaluating mathematical modelling problems. International Journal of Research in Education and Science, 5(2), 730-743.

Schukajlow, S., Kaiser, G., \& Stillman, G. (2018). Empirical research on teaching and learning of mathematical modelling: a survey on the current state-of-the-art. ZDM Mathematics Education, 5O(1-2), 5-18.

Stein, M. K., Grover, B. W., \& Henningsen, M. (1996). Building student capacity for mathematical thinking and reasoning: An analysis of mathematical tasks used in reform classroom. American Educational Research Journal, 33(2), 455- 488.

Tichà, M. \& Hošpesovà, A. (2010). Problem posing and development of pedagogical content knowledge in preservice teacher training. In Proceedings of the Sixth Congress of the European Society for Research in Mathematics Education (CERME). pp. 1941-1950. Lyon, France. 